\title{
Inadequacy of Vitamin D Nutritional Status in Individuals with Metabolically Unhealthy Obesity Phenotype: The Relevance of Insulin Resistance
}

This article was published in the following Dove Press journal: Diabetes, Metabolic Syndrome and Obesity: Targets and Therapy

\author{
A Cordeiro (iD) ${ }^{1,2}$ \\ B Campos ${ }^{3}$ \\ SE Pereira (1D) \\ C) Saboya $\mathbb{D}^{3}$
}

A Ramalho'

'Department of Social Applied Nutrition, Micronutrients Research Center (NPqM), Institute of Nutrition, Federal University of Rio de Janeiro (UFRJ), Rio de Janeiro, Brazil; ${ }^{2}$ Department of Biomedicine, Unit of Biochemistry, Faculty of Medicine of the University of Porto (FMUP), Porto, Portugal; ${ }^{3}$ Multidisciplinary Center of Bariatric and Metabolic Surgery Carlos Saboya, Rio de Janeiro, Brazil
Correspondence: A Cordeiro

Al. Prof. Hernâni Monteiro, Porto 4200 319 , Portugal

Tel +35I-966669689

Fax +35I 220426937

Email cordeiroadryana@gmail.com
Purpose: The aim was to evaluate $25(\mathrm{OH}) \mathrm{D}$ serum concentrations in metabolically healthy obesity (MHO) and metabolically unhealthy obesity (MUHO) and its relation with biochemical and clinical parameters in both groups according to homeostatic model assessmentinsulin resistance (HOMA-IR) definition of the obesity phenotypes.

Patients and Methods: Descriptive cross-sectional study was conducted with individuals of both genders. Anthropometric data [waist circumference, body mass index (BMI)] and metabolic parameters: blood glucose, glycated hemoglobin, insulin, lipid profile, calcium, phosphorus, parathyroid hormone (PTH) and high-sensitivity c-reactive protein (hs-CRP) and $(25(\mathrm{OH}) \mathrm{D})$ were obtained. The cutoff points for vitamin D deficiency and insufficiency were $\leq 20$ and $21-29 \mathrm{ng} / \mathrm{mL}$, respectively. Individuals were classified as MUHO according to HOMA-IR $\geq 2.5$.

Results: This study comprised 232 individuals with obesity (BMI $\geq 35 \mathrm{~kg} / \mathrm{m}^{2} ; 42.6 \pm 4.7 \mathrm{~kg} /$ $\mathrm{m}^{2}$ ). The MUHO phenotype was observed in $76.7 \%$ of the population. The mean values of glucose $(P<0.001)$, insulin $(P<0.001)$, HOMA-IR $(P<0.001)$, and triglycerides $(P=0.049)$ were significantly higher in the MUHO than in the MHO phenotype group. The mean value of 25(OH)D showed a significant difference between the MHO and MUHO phenotype groups $(P=0.011)$. Additionally, and in line, lower mean $25(\mathrm{OH}) \mathrm{D}$ values were found in the MUHO vs the MHO phenotype group in the deficiency $(14.5 \pm 3.6 \mathrm{ng} / \mathrm{mL} / 17.1 \pm 2.7 \mathrm{ng} /$ $\mathrm{mL}, P=0.004)$ and insufficiency $(24.5 \pm 2.9 \mathrm{ng} / \mathrm{mL} / 25.7 \pm 2.6 \mathrm{ng} / \mathrm{mL}, P=0.077) 25(\mathrm{OH}) \mathrm{D}$ groups. An increase of $1 \mathrm{ng} / \mathrm{mL}$ of vitamin D increased in $1.051(95 \% \mathrm{CI}=1.011-1.093$, $P=0.012$ ) the odds of the healthy phenotype.

Conclusion: The highest prevalence of inadequacy of serum concentrations of $25(\mathrm{OH}) \mathrm{D}$ and greater severity of this deficiency in individuals with MUHO phenotype were observed. Low serum concentrations of this vitamin were associated, mainly, with insulin resistance. Monitoring the nutritional status of vitamin D in individuals with obesity that present with MUHO phenotype may contribute to minimize the occurrence and aggravation of diseases associated with obesity.

Keywords: metabolically healthy obesity, nutritional status, $25(\mathrm{OH}) \mathrm{D}$, metabolic diseases

\section{Introduction}

The prevalence of obesity has been increasing exponentially in recent years and it is the fifth greatest risk factor for mortality ${ }^{1}$ worldwide. It also presents as a risk factor for complications such as type 2 diabetes mellitus (T2DM), dyslipidemia, hypertension, and cardiovascular diseases, besides metabolic syndrome. ${ }^{2}$ In spite of the fact that obesity is the major starting factor for metabolic complications, there is a group 
of individuals with obesity that appear to be more protected from metabolic disorders, and these are called the metabolically healthy obesity (MHO) group. MHO is defined as subjects with obesity that has insulin sensitivity in the absence of diabetes, dyslipidemia, or hypertension. The prevalence of $\mathrm{MHO}$ was found in $20-30 \%$ of individuals with obesity. ${ }^{3}$ Studies show that MHO may have lower risk factors for cardiovascular events and mortality compared to metabolically unhealthy obesity (MUHO) subjects. $^{4,5}$

Vitamin D (VD) is essential for the development and maintenance of bone tissue, as well as for normal homeostasis of calcium and phosphorus. ${ }^{6}$ Moreover, VD has other major functional roles; according to the expression of its receptor in various cell types it may be engaged in multiple cellular processes, including the response to insulin. It is an important nutrient with a crucial role in obesity and in the comorbidities associated with the chronic inflammation. ${ }^{7}$ Several studies have shown the relationship between obesity (body mass index $[\mathrm{BMI}] \geq 30 \mathrm{~kg} / \mathrm{m}^{2}$ ) with low serum $25(\mathrm{OH}) \mathrm{D}^{8-12}$

Some cross-sectional studies have reported inverse associations of higher serum $25(\mathrm{OH}) \mathrm{D}$ concentrations with lower prevalence of metabolic syndrome. ${ }^{13-16}$ A study that used only Homeostatic model assessmentinsulin resistance (HOMA-IR) to classify phenotype MHO showed high prevalence of vitamin D deficiency (VDD) in individuals with obesity, correlating $25(\mathrm{OH}) \mathrm{D}$ levels with the degree of adiposity, but not related to metabolic health status. ${ }^{17}$ Usually, studies that relate VDD with phenotypes of obesity use classification of National Cholesterol Education Program's/Adult Treatment Panel III (NCEP/ ATP III) and HOMA-IR.

The aim was to evaluate $25(\mathrm{OH}) \mathrm{D}$ serum concentrations, consequently, VD status in $\mathrm{MHO}$ and $\mathrm{MUHO}$ and its relationship with biochemical and clinical parameters in both groups according to HOMA-IR definition of the obesity phenotypes.

\section{Patients and Methods}

This study comprised 232 individuals with obesity (body mass index $\left.(B M I) \geq 35 \mathrm{~kg} / \mathrm{m}^{2} ; 42.6 \pm 4.7 \mathrm{~kg} / \mathrm{m}^{2}\right)$, recruited within the patients of a medical clinic specialized in obesity control, in the municipality of Rio de Janeiro, Brazil, from November 2016 to July 2018.

All patients were informed that participation in the study is voluntary and that refusal to participate as well as stopping at any time without giving reasons and without any consequences is possible.

Written informed consent was obtained before carrying out any study-related procedures from all subjects who participated in the study. This study was conducted in accordance with the Declaration of Helsinki. Exclusion criteria were as follows: pregnancy or lactation, history and/or presence of chronic kidney (defined by estimated GFR $<60 \mathrm{~mL} / \mathrm{min} / 1.73 \mathrm{~m}^{2}$ ) or liver diseases (except nonalcoholic fatty liver disease), acute or chronic infections, hyperparathyroidism or elevated serum calcium levels, malabsorption bowel syndrome, previous restrictive and disabsorptive surgeries, diagnosis of endocrinopathies (hyperparathyroidism, hypothyroidism, hypercortisolemia), use of anticonvulsant medications or drugs known to interfere with vitamin D metabolism, as well as current insulin treatment and consumption or prescription of vitamin D supplements within 6 months prior to blood work. This study was approved by the Research Ethics Committee of Hospital Universitário Clementino Fraga Filho, Federal University of Rio de Janeiro, Brazil (Research Protocol number 011/06-CEP).

\section{Sample Size}

The sample size was determined to respond to the aim of the study. The following parameters have been assumed: use of bilateral tests, a level of significance of $5 \%$, a statistical power of $80 \%$, and an expected correlation of -0.25 .

A necessary sample size of 224 individuals was obtained. The sample size value was inflated by $10 \%$ to anticipate possible losses.

\section{Evaluation of Anthropometric Parameters} BMI calculation $\left(\mathrm{kg} / \mathrm{m}^{2}\right)$ was conducted based on the anthropometric measurements of weight $(\mathrm{kg})$ and height (m). ${ }^{18}$ The measurement of the diameter $(\mathrm{cm})$ of the waist circumference (WC) was performed with the volunteer standing straight, the abdomen relaxed, the arms beside the body, and the feet together. A non-extensible tape was used to involve the subject in the greatest abdominal diameter, being the diameter of the $\mathrm{WC}$ evaluated at the completion of the individual normal expiration. The volunteers were wearing only underwear when these features were assessed.

\section{Evaluation of Systemic Blood Pressure}

The blood pressure quantification by indirect measurement method was carried out using a OMRON HEM-705CP 
monitor (OMRON Healthcare Europe B.V., Hoofddorp, Netherlands), with a range of $0-300 \mathrm{mmHg}$ and an accuracy of $\pm 3 \mathrm{mmHg}$. At least two measurements were taken, with an interval of about 1 minute, and the mean was calculated.

\section{Evaluation of Circulating Biochemical and Metabolic Parameters}

For biochemical and metabolic evaluation, blood was obtained by venipuncture, after an overnight fasting period for 12 hours. Laboratory tests were conducted in the serum to characterize the lipid profile [total cholesterol, lowdensity lipoprotein cholesterol (LDL-c), high-density lipoprotein cholesterol (HDL-c), and triglycerides (TG)] and to evaluate glucose, hemoglobin A1c (HbA1c), insulin, calcium, phosphorus, parathyroid hormone (PTH) and high-sensitivity c-reactive protein (hs-CRP) levels. Determinations of total cholesterol, HDL-c, triglycerides, and glucose were performed using specific enzymatic colorimetric methods (Labtest Diagnóstica S.A., Minas Gerais, Brazil). LDL-c fraction was calculated in accordance with the Friedewald's formula. ${ }^{19} \mathrm{HbA1c}$ measurements were performed using high-performance liquid chromatography (HPLC)(HumaNexA1c system, Human, Wiesbaden, Germany). Insulin was quantified using reversed-phase HPLC (Labtest Diagnóstica S.A., Minas Gerais, Brazil). hs-CRP was analyzed using the Tinaquant $^{\circledR}$ C-reactive protein latex ultrasensitive assay (Roche Diagnostics GmbH, Mannheim, Germany). PTH measurements were performed by an electrochemiluminescence immunoassay (ECLIA) using Modular E170 (Roche Diagnostics GmbH). Serum calcium and phosphorus concentrations were analyzed with a routine autoanalyzer (Roche Diagnostics, Modular P 800, Indianapolis, USA).

HOMA-IR was calculated as follows: fasting insulin $(\mu \mathrm{IU} / \mathrm{mL}) \times$ fasting glucose $(\mathrm{mg} / \mathrm{dL}) / 405 .^{20}$

\section{Vitamin D Status}

Serum vitamin D analysis was conducted in the form of 25 $(\mathrm{OH}) \mathrm{D}$ using HPLC with ultraviolet (UV) detector (Chromsystems, BioSysLtda, Rio de Janeiro, Brazil). The volunteers of this study were organized according to the 25 $(\mathrm{OH}) \mathrm{D}$ cutoff points of the clinical practice guideline of the American Endocrine Society ${ }^{21}$ and included in the deficiency $(\leq 20 \mathrm{ng} / \mathrm{mL})$, insufficiency $(21-29 \mathrm{ng} / \mathrm{mL})$ or sufficiency $(\geq 30-<100 \mathrm{ng} / \mathrm{mL})$ groups.
To complete the evaluation of the nutritional status of vitamin D, an investigation was conducted on the sun exposure of the individuals, as described by Hanwell et al. ${ }^{22}$

\section{Definitions of the Metabolically Healthy and Unhealthy Obesity Phenotypes}

Participants were divided in two obesity phenotype groups, MHO and MUHO, according to HOMA-IR $\geq 2.5$. $^{5}$

\section{Statistical Analysis}

Statistical analysis was performed using the SPSS software (SPSS version 17.0, Chicago, IL, USA). Categorical variables were reported as count and percentage, while numerical variables were described as mean \pm standard deviation (SD). Proportion differences between the MHO and MUHO phenotype groups were evaluated using the chi-square test. Differences between the MHO and MUHO phenotype groups in the continuous variables were assessed using the two-independent sample $t$-test (Tables 1 and 2). Correlation analysis of $25(\mathrm{OH}) \mathrm{D}$ levels with the other anthropometric, biochemical and metabolic parameters were estimated using the Pearson's or Spearman correlation (considering if the distribution of the variables was symmetric or not, respectively) (Table 3).

A repeated-measures ANCOVA analysis was used to evaluate the differences regarding biochemical and anthropometric variables between the groups while adjusted for WC (Table 4) and for lipid profile, glycemic indexes, and hs-CRP (Table 5). Unconditional multiple logistic regression was used to estimate the adjusted odds ratio (OR) between the $25(\mathrm{OH}) \mathrm{D}$ levels and the MHO phenotype group as well as the respective $95 \%$ confidence interval. $P$-values $\leq 0.05$ were considered statistically significant (a tendency was considered whenever $0.05<P \leq 0.8$ ).

\section{Results \\ General Characteristics}

Table 1 shows the anthropometric, biochemical, and metabolic parameters of our population analyzed according to the definition taken into consideration for the classification of the obesity phenotype. The MUHO phenotype was observed in $76.7 \%$ of the population. The sample was comprised of 178 females $(76.7 \%)$, mean age $42.0 \pm 10.7$ years $(21 \leq$ age $\geq 59$ years), and $21.6 \%(n=50)$ had T2DM. There were no significant differences for BMI and body weight mean values, as well as for gender, between MHO and MUHO. However, 
Table I Anthropometric, Biochemical and Metabolic Parameters of the MHO and MUHO Phenotype Groups According to the HOMA-IR Obesity Phenotype Definition

\begin{tabular}{|c|c|c|c|}
\hline & \multicolumn{2}{|l|}{ HOMA-IR } & \multirow[t]{2}{*}{$P$} \\
\hline & МHO & MUHO & \\
\hline Number & 54 & 178 & \\
\hline $\begin{array}{l}\text { Gender, } \mathrm{n}(\%) \text { Male } \\
\text { Female }\end{array}$ & $\begin{array}{l}10(18.5) \\
44(81.5)\end{array}$ & $\begin{array}{l}44(24.7) \\
\text { I } 34(75.3)\end{array}$ & 0.345 \\
\hline Age (years) & $42.5 \pm 9.9$ & $41.8 \pm 10.9$ & 0.662 \\
\hline BMI $\left(\mathrm{kg} / \mathrm{m}^{2}\right)$ & $41.8 \pm 3.8$ & $42.8 \pm 5.0$ & 0.204 \\
\hline Weight (kg) & $116.5 \pm 18.1$ & $118.0 \pm 19.1$ & 0.593 \\
\hline$W C(\mathrm{~cm})$ & $116.4 \pm 13.1$ & $120.6 \pm 13.3$ & $0.04 I^{\mathrm{a}}$ \\
\hline Cholesterol (mg/dL) & $185.9 \pm 34.5$ & $203.7 \pm 56.0$ & $0.029^{a}$ \\
\hline LDL-c (mg/dL) & $112.7 \pm 28.2$ & $123.03 \pm 38.8$ & $0.034^{\mathrm{a}}$ \\
\hline HDL-c (mg/dL) & $48.1 \pm 12.4$ & $45.6 \pm 11.1$ & 0.165 \\
\hline TG (mg/dL) & $118.0 \pm 67.8$ & $182.4 \pm 235.7$ & $0.049^{a}$ \\
\hline Glucose (mg/dL) & $89.3 \pm 8.4$ & $105.2 \pm 29.8$ & $<0.001^{b}$ \\
\hline HbAlc (\%) & $5.3 \pm 0.4$ & $6.2 \pm 3.5$ & 0.059 \\
\hline Insulin ( $\mu \mathrm{IU} / \mathrm{mL})$ & $8.0 \pm 2.2$ & $21.6 \pm 10.3$ & $<0.00 \mathrm{I}^{\mathrm{b}}$ \\
\hline HOMA-IR & $1.7 \pm 0.5$ & $5.7 \pm 3.8$ & $<0.00 \mathrm{I}^{\mathrm{b}}$ \\
\hline Calcium (mg/dL) & $4.0 \pm 1.3$ & $3.8 \pm 1.8$ & 0.389 \\
\hline Phosphorus (mg/dL) & $3.4 \pm 0.6$ & $3.6 \pm 0.6$ & 0.074 \\
\hline PTH (pg/mL) & $44.4 \pm 20.2$ & $42.0 \pm 15.4$ & 0.336 \\
\hline hs-CRP (mg/dL) & $0.7 \pm 0.6$ & $1.0 \pm 0.9$ & $0.029^{\mathrm{a}}$ \\
\hline $\mathrm{SBP}(\mathrm{mmHg})$ & $138.2 \pm 32.4$ & $133.9 \pm 28.4$ & 0.340 \\
\hline $\mathrm{DBP}(\mathrm{mmHg})$ & $88.3 \pm 27.4$ & $85.0 \pm 22.0$ & 0.421 \\
\hline \multicolumn{4}{|l|}{ Hypertension, n (\%) } \\
\hline Yes & $21(38.9)$ & $94(52.8)$ & \\
\hline No & $33(61.1)$ & $84(47.2)$ & 0.073 \\
\hline \multicolumn{4}{|l|}{ T2DM, n (\%) } \\
\hline Yes & $4(7.4)$ & $46(25.8)$ & \\
\hline No & $50(92.6)$ & I 32 (74.2) & $0.004^{b}$ \\
\hline
\end{tabular}

Notes: Values are presented as mean $\pm S D$ or as count (and percentage); Differences between groups were assessed with two-independent sample $t$-test or Chi-square test; ${ }^{a} P<0.05 ;{ }^{b} P<0.01$.

Abbreviations: BMI, body mass index; DBP, diastolic blood pressure; T2DM, type 2 diabetes mellitus; hs-CRP, high-sensitive c-reactive protein; LDL-c, low-density lipoprotein cholesterol; HbAlc, glycated hemoglobin; HDL-c, high-density lipoprotein cholesterol; HOMA-IR, homoeostasis model assessment-insulin resistance; $\mathrm{MHO}$, metabolically healthy obesity; $\mathrm{MUHO}$, metabolically unhealthy obesity; PTH, parathyroid hormone; SBP, systolic blood pressure; TG, triglycerides; WC, waist circumference.

WC diameter was significantly higher in the MUHO than in the MHO phenotype group $(P=0.041)$. The mean values of glucose $(P<0.001)$, insulin $(P<0.001)$, HOMA-IR $(P<0.001)$, and triglycerides $(P=0.049)$ were significantly higher in the MUHO than in the MHO phenotype group. Glycated hemoglobin means levels presented a tendency to be higher in the MUHO than in the MHO phenotype group $(P=0.059)$. Significantly higher percentages of $\mathrm{MHO}$ without T2DM were observed $(92.6 \%, P=0.004)$. Total cholesterol mean
Table 2 Nutritional Status of Vitamin D [25(OH)D] and Time of Sun Exposure (Minutes) of the MHO and MUHO Phenotype Groups According to the HOMA-IR Obesity Phenotype Definition

\begin{tabular}{|l|l|l|l|}
\hline \multirow{2}{*}{} & \multicolumn{2}{|l|}{ HOMA-IR } & \multirow{2}{*}{$\boldsymbol{P}$} \\
\cline { 2 - 3 } & MHO & MUHO & \\
\cline { 2 - 3 } & $\mathbf{( n = 5 4 )}$ & $\mathbf{( n = 1 7 8 )}$ & \\
\hline $25(\mathrm{OH}) \mathrm{D}(\mathrm{ng} / \mathrm{mL})$ & $24.9 \pm 8.0$ & $21.8 \pm 7.9$ & $0.01 I^{\mathrm{a}}$ \\
Deficiency & $17.1 \pm 2.7$ & $14.5 \pm 3.6$ & $0.004^{\mathrm{b}}$ \\
$(\leq 20 \mathrm{ng} / \mathrm{mL})$ & $19(35.2 \%)$ & $74(41.6 \%)$ & \\
Time of sun exposure (minutes) & $8.7 \pm 2.1$ & $8.2 \pm 3.4$ & 0.514 \\
Insufficiency & $25.7 \pm 2.6$ & $24.5 \pm 2.9$ & 0.077 \\
$(2 \mathrm{I}-29 \mathrm{ng} / \mathrm{mL})$ & $24(44.4 \%)$ & $78(43.8 \%)$ & \\
Time of sun exposure (minutes) & $8.5 \pm 2.4$ & $9.1 \pm 3.6$ & 0.433 \\
Sufficiency & $36.9 \pm 6.2$ & $34.2 \pm 6.4$ & 0.257 \\
( $\geq 30 \mathrm{ng} / \mathrm{mL})$ & $11(20.4 \%)$ & $26(14.6 \%)$ & \\
Time of sun exposure (minutes) & $8.4 \pm 3.0$ & $9.3 \pm 4.1$ & 0.279 \\
2 & & & 0.525 \\
\hline
\end{tabular}

Notes: Values are presented as mean $\pm S D$ or as count (and percentage); Differences between groups were assessed with 'two-independent sample $t$-test (within each obesity phenotype definition) or ${ }^{2} \mathrm{Chi}$-square test (within each obesity phenotype definition considering the prevalence of the three vitamin $D$ nutritional status groups); ${ }^{\mathrm{P}}<0.05$; ${ }^{\mathrm{b}} \mathrm{P}<0.01$.

Abbreviations: HOMA-IR, homeostatic model assessment-insulin resistance; MHO, metabolically healthy obesity; MUHO, metabolically unhealthy obesity.

results were higher in the MUHO than in the MHO phenotype group $(P=0.029)$. In agreement, the same happened for LDL-c and hs-CRP mean values ( $P=0.034$ and 0.029 , respectively). Mean phosphorus value tended to be higher in MUHO than in MHO phenotype group $(P=0.074)$. The results showed a tendency for higher percentage of $\mathrm{MHO}$ without hypertension $(61.1 \%, P=0.073)$.

\section{Vitamin D Nutritional Status}

Table 2 presents the $25(\mathrm{OH}) \mathrm{D}$ nutritional status of the $\mathrm{MHO}$ and MUHO phenotype groups. The mean value of $25(\mathrm{OH}) \mathrm{D}$ showed a significant difference between the $\mathrm{MHO}$ and MUHO phenotype groups $(P=0.011)$. Additionally, and in line, lower mean $25(\mathrm{OH}) \mathrm{D}$ values were found in the MUHO versus the MHO phenotype group in the deficiency $(P=0.004)$ and insufficiency $(P=0.077) 25(\mathrm{OH}) \mathrm{D}$ groups. No difference was found for prevalence of $25(\mathrm{OH}) \mathrm{D}$ deficiency nor sun exposure time between $\mathrm{MHO}$ and MUHO (Table 2).

A significant negative correlation between vitamin $\mathrm{D}$ nutritional status and BMI $(\mathrm{r}=-0.131, P=0.047)$, insulin $(\mathrm{r}=-0.176, P=0.007)$ and HOMA-IR $(\mathrm{r}=-0.182 ; P=0.005)$ was found. Furthermore, systolic $(\mathrm{r}=-0.121, P=0.066)$ and diastolic $(\mathrm{r}=-0.111, P=0.093)$ blood pressure showed a tendency (Table 3). 
Table 3 Correlation Between Vitamin D [25(OH)D] and Anthropometric, Biochemical and Metabolic Parameters

\begin{tabular}{|l|l|l|}
\hline Parameters & $\boldsymbol{r}$ & $\boldsymbol{P}$ \\
\hline Age (years) & 0.015 & 0.823 \\
BMI (kg/m²) & -0.131 & $0.047^{\mathrm{a}}$ \\
Weight (kg) & -0.070 & 0.290 \\
WC (cm) & -0.017 & 0.797 \\
Cholesterol (mg/dL) & -0.035 & 0.596 \\
LDL-c (mg/dL) & -0.034 & 0.607 \\
HDL-c (mg/dL) & -0.024 & 0.714 \\
TG (mg/dL) & -0.102 & 0.120 \\
Glucose (mg/dL) & -0.048 & 0.468 \\
*HbAlc (\%) & -0.068 & 0.306 \\
*Insulin (mcU/mL) & -0.176 & $0.007^{\mathrm{b}}$ \\
*HOMA-IR & -0.182 & $0.005^{\mathrm{b}}$ \\
Calcium (mg/dL) & 0.049 & 0.459 \\
*Phosphorus (mg/dL) & -0.073 & 0.271 \\
*PTH (pg/mL) & 0.075 & 0.257 \\
hs-CRP (mg/dL) & $<0.001$ & 0.997 \\
SBP (mmHg) & -0.121 & 0.066 \\
DBP (mmHg) & $-0.11 \mathrm{l}$ & 0.093 \\
\hline
\end{tabular}

Notes: Pearson or $*$ Spearman correlation; ${ }^{\mathrm{a}} P<0.05 ;{ }^{\mathrm{b}} \mathrm{P}<0.0 \mathrm{I}$.

Abbreviations: BMI, body mass index; DBP, diastolic blood pressure; hs-CRP, high-sensitive c-reactive protein; LDL-c, low-density lipoprotein cholesterol; $\mathrm{HbAlc}$, glycated hemoglobin; HDL-c, high-density lipoprotein cholesterol; HOMA$\mathrm{IR}$, homeostatic model assessment-insulin resistance; PTH, parathyroid hormone; SBP, systolic blood pressure; TG, triglycerides; WC, waist circumference.

We analyzed biochemical and anthropometric variables between $\mathrm{MHO}$ and MUHO groups while adjusting for WC, and significant differences were shown with BMI, weight, glycemic parameters, and $25(\mathrm{OH}) \mathrm{D}$ (Table 4) and while adjusting for lipid profile, glycemic indexes, and hsCRP, shown about WC and DBP (Table 5). We observed an increase of $1 \mathrm{ng} / \mathrm{mL}$ of vitamin $\mathrm{D}$ increased in 1.051 (95\% CI $=1.011-1.093, P=0.012)$ the odds of the healthy phenotype.

\section{Discussion}

The present study observed, in accordance with HOMA-IR criteria adopted to classify obesity phenotype, the prevalence of MUHO was higher than MHO in our population. Studies suggest that MUHO is characterized by a lower inflammatory cytokine environment than $\mathrm{MHO}^{23-25}$ and the last phenotype may be caused by several mechanisms, ${ }^{26}$ including preserved insulin sensitivity, specific fat distribution with low visceral and ectopic fat accumulation compared with subcutaneous fat depots, normal adipose tissue function defined by lower adipocyte size, less macrophage infiltration into adipose tissue, ${ }^{27}$ and normal adipokine secretion. ${ }^{26,28}$ However, more studies are necessary to identify the mechanisms that promote a healthy metabolic profile in individuals with obesity.

According to the nutritional status of vitamin $\mathrm{D}$ in obesity phenotypes, a significant difference was detected between both groups ( $\mathrm{MHO}$ and $\mathrm{MUHO}$ ), presenting high prevalence of inadequacy and lowest mean in MUHO. Additionally, our study demonstrated that an increase of vitamin D serum concentrations increased the odds ratio of occurrence of the MHO phenotype. These findings can be answered by the fact that low concentrations of 25 $(\mathrm{OH}) \mathrm{D}$ were associated with insulin resistance (IR). The literature has shown that prediabetes is associated with vitamin D insufficiency, and VDD has been found to be more prevalent in diabetic patients compared to people without diabetes. Thus, VD is proposed to prevent the progression of glucose intolerance. The putative underlying mechanisms include maintaining intracellular calcium concentration, direct stimulation of insulin receptor expression, and increased insulin response to glucose transporters. $^{29}$ VD may modulate insulin action and enhance insulin responsiveness by direct stimulation of insulin receptor gene. ${ }^{30}$ The influence of IR on nutritional status of VD, causing potential mechanisms that link VDD to increased diabetes risk, have yet to be established but may involve increased inflammation owing to unregulated increase in the activity of the nuclear factor-kappa B (NFkB) signaling pathway. ${ }^{31}$ Inflammation promotes this metabolic upset that is a pathological situation characterized by a lack of physiological response of peripheral tissues to insulin action, leading to the metabolic and hemodynamic disturbances and is a characteristic feature of T2DM and strongly associated with cardiovascular diseases. $^{32}$

Therefore, scientific evidence suggests that calcitriol has a strong anti-inflammatory effect and consequently reduces systemic inflammation. ${ }^{33}$ Vitamin D3 (VD3) improves insulin sensitivity, at least partially, attenuating inflammatory effects. ${ }^{34}$ The insulin sensitivity effects of VD3 depend on its potential anti-inflammatory via lipogenic SCAP4/SREBP5, seen in diabetic mice. It has also been reported that VDR in conjunction with calcitriol is able to attenuate the transcriptional activity of $\mathrm{NF}-\kappa \mathrm{B}$ through the reduced degradation of $\mathrm{I} \kappa \mathrm{B} \alpha$ in cotransfected HEK-293 cells. Calcitriol is able to neutralize the effects of FGF-23 in inducing TNF- $\alpha$ in RAW 264 cells. $^{7}$ 
Table 4 Biochemical and Clinical Parameters of the MHO and MUHO Phenotype Groups According to the HOMA-IR Obesity Phenotype Definition Adjusted for WC

\begin{tabular}{|c|c|c|c|c|c|c|c|}
\hline \multirow[t]{4}{*}{ Variables } & \multicolumn{6}{|l|}{ HOMA-IR } & \multirow[t]{4}{*}{$P$} \\
\hline & \multicolumn{3}{|l|}{ МНO } & \multicolumn{3}{|l|}{ MUHO } & \\
\hline & \multirow[t]{2}{*}{ Mean \pm SE } & \multicolumn{2}{|l|}{$95 \% \mathrm{Cl}$} & \multirow[t]{2}{*}{ Mean士SE } & \multicolumn{2}{|l|}{$95 \% \mathrm{Cl}$} & \\
\hline & & Lower & Upper & & Lower & Upper & \\
\hline BMI $\left(\mathrm{kg} / \mathrm{m}^{2}\right)$ & $41.8 \pm 0.5$ & 40.9 & 42.8 & $42.8 \pm 0.3$ & 42.2 & 43.4 & $0.001^{b}$ \\
\hline Weight (kg) & $116.5 \pm 1.9$ & 112.7 & 120.2 & $118.0 \pm 1.0$ & 116.0 & 120.0 & $0.040^{\mathrm{a}}$ \\
\hline LDL-c (mg/dL) & $112.7 \pm 3.8$ & 105.0 & 120.5 & $123.0 \pm 2.9$ & 117.3 & 128.7 & 0.084 \\
\hline HDL-c (mg/dL) & $48.1 \pm 1.7$ & 44.7 & 51.5 & $45.6 \pm 0.8$ & 44.0 & 47.2 & 0.182 \\
\hline TG (mg/dL) & $118.0 \pm 9.1$ & 99.7 & 136.3 & $182.4 \pm \mid 7.7$ & 147.4 & 217.3 & 0.151 \\
\hline Glucose (mg/dL) & $89.3 \pm 1.1$ & 86.9 & 91.6 & $105.2 \pm 2.2$ & 100.8 & 109.6 & $0.002^{\mathrm{b}}$ \\
\hline HbAlc (\%) & $5.3 \pm 0.5$ & 5.2 & 5.4 & $6.2 \pm 0.2$ & 5.7 & 6.7 & $0.040^{\mathrm{a}}$ \\
\hline Insulin ( $\mu \mathrm{IU} / \mathrm{mL})$ & $8.0 \pm 0.3$ & 7.4 & 8.6 & $21.6 \pm 0.7$ & 20.1 & 23.1 & $0.003^{b}$ \\
\hline HOMA-IR & $1.7 \pm 0.6$ & 1.7 & 1.9 & $5.7 \pm 0.3$ & 5.2 & 6.2 & $0.004^{b}$ \\
\hline $25(\mathrm{OH}) \mathrm{D}(\mathrm{ng} / \mathrm{mL})$ & $24.9 \pm 1.1$ & 22.8 & 27.1 & $21.8 \pm 0.6$ & 20.6 & 22.9 & $0.020^{\mathrm{a}}$ \\
\hline Calcium (mg/dL) & $4.0 \pm 0.2$ & 3.7 & 4.4 & $3.8 \pm 0.1$ & 3.6 & 4.1 & 0.353 \\
\hline Phosphorus (mg/dL) & $3.4 \pm 0.1$ & 3.3 & 3.6 & $3.6 \pm 0.5$ & 3.5 & 3.7 & 0.370 \\
\hline PTH (pg/mL) & $44.4 \pm 2.8$ & 38.9 & 50.0 & $42.0 \pm 1.1$ & 39.7 & 44.2 & 0.467 \\
\hline hs-CRP (mg/dL) & $0.7 \pm 0.8$ & 0.6 & 0.9 & $1.0 \pm 0.7$ & 0.8 & I.I & 0.154 \\
\hline $\mathrm{SBP}(\mathrm{mmHg})$ & $137.6 \pm 4.3$ & 128.7 & 146.2 & $133.5 \pm 2.1$ & 129.3 & 137.8 & 0.070 \\
\hline $\mathrm{DBP}(\mathrm{mmHg})$ & $88.3 \pm 3.6$ & 81.0 & 95.6 & $85.0 \pm 22.0$ & 81.7 & 88.2 & 0.067 \\
\hline
\end{tabular}

Notes: Values are presented as mean \pm SE or as count (and percentage); Differences between groups were assessed with ANCOVA; ${ }^{a} P<0.05$; ${ }^{b} P<0.01$.

Abbreviations: BMI, body mass index; DBP, diastolic blood pressure; T2DM, type 2 diabetes mellitus; hs-CRP, high-sensitive c-reactive protein; LDL-c, low-density lipoprotein cholesterol; HbAlc, glycated hemoglobin; HDL-c, high-density lipoprotein cholesterol; HOMA-IR, homoeostasis model assessment-insulin resistance; MHO, metabolically healthy obesity; MUHO, metabolically unhealthy obesity; PTH, parathyroid hormone; SBP, systolic blood pressure; TG, triglycerides.

Table 5 Biochemical and Clinical Parameters of the MHO and MUHO Phenotype Groups According to the HOMA-IR Obesity Phenotype Definition Adjusted for Lipid Profile, Glycemic Indexes, and Hs-CRP

\begin{tabular}{|c|c|c|c|c|c|c|c|}
\hline \multirow[t]{3}{*}{ Variables } & \multicolumn{6}{|l|}{ HOMA-IR } & \multirow[t]{3}{*}{$P$} \\
\hline & \multicolumn{3}{|l|}{ MHO } & \multicolumn{3}{|l|}{ MUHO } & \\
\hline & Mean \pm SE & \multicolumn{2}{|c|}{$95 \% \mathrm{Cl}$} & Mean \pm SE & \multicolumn{2}{|c|}{$95 \% \mathrm{Cl}$} & \\
\hline BMI $\left(\mathrm{kg} / \mathrm{m}^{2}\right)$ & $41.8 \pm 0.5$ & 40.8 & 42.9 & $42.8 \pm 0.4$ & 42.1 & 43.5 & 0.149 \\
\hline Weight (kg) & $116.5 \pm 2.3$ & 111.9 & 121.0 & $118.0 \pm 1.4$ & 115.3 & 120.8 & 0.058 \\
\hline$W C(\mathrm{~cm})$ & $116.4 \pm 1.6$ & 113.2 & 119.6 & $120.6 \pm 0.9$ & 118.7 & 122.5 & $0.034^{a}$ \\
\hline $25(\mathrm{OH}) \mathrm{D}(\mathrm{ng} / \mathrm{mL})$ & $24.9 \pm 1.1$ & 22.7 & 27.2 & $21.7 \pm 0.6$ & 20.6 & 22.9 & 0.653 \\
\hline Calcium (mg/dL) & $4.0 \pm 0.1$ & 3.7 & 4.4 & $3.8 \pm 0.1$ & 3.6 & 4.1 & 0.254 \\
\hline Phosphorus (mg/dL) & $3.5 \pm 0.1$ & 3.3 & 3.6 & $3.6 \pm 0.4$ & 3.5 & 3.7 & 0.097 \\
\hline PTH (pg/mL) & $44.5 \pm 2.7$ & 39.9 & 49.9 & $42.0 \pm 1.1$ & 39.6 & 44.3 & 0.350 \\
\hline $\mathrm{SBP}(\mathrm{mmHg})$ & $137.5 \pm 4.0$ & 129.3 & 145.6 & $133.5 \pm 2.1$ & 129.3 & 137.7 & 0.438 \\
\hline $\mathrm{DBP}(\mathrm{mmHg})$ & $88.3 \pm 3.4$ & 81.7 & 95.2 & $84.9 \pm 1.6$ & 81.7 & 88.2 & $0.038^{\circ}$ \\
\hline
\end{tabular}

Notes: Values are presented as mean \pm SE or as count (and percentage); Differences between groups were assessed with ANCOVA; ${ }^{2} P<0.05$.

Abbreviations: BMI, body mass index; DBP, diastolic blood pressure; T2DM, type 2 diabetes mellitus; MHO, metabolically healthy obesity; MUHO, metabolically unhealthy obesity; PTH, parathyroid hormone; SBP, systolic blood pressure; WC, waist circumference.

We observed that the variables such as glucose, insulin, HOMA-IR, and TG presented significant differences between two obesity phenotypes. There is evidence to suggest that VD negatively correlated with IR, insulin secretion, the number of components of the metabolic syndrome (MS), subclinical inflammation. ${ }^{35}$ VD seems to play an important role in the maintenance of pancreatic $\beta$ cell function and the correction of VDD improves insulin secretion and prevents the development of abnormalities in glucose homeostasis. ${ }^{36}$ Moreover, this vitamin may 
modulate IR pathways associated with T2DM related obesity in many ways: 1$)$ active vitamin $\mathrm{D}(1,25(\mathrm{OH}) 2 \mathrm{D} 3)$ increases peroxisome proliferator-activated receptor delta (PPAR- $\delta$ ) gene expression, which PPAR- $\delta$ is often coexpressed with vitamin $\mathrm{D}$ receptor (VDR) and has been shown to favorably affect fatty cell accumulation and fatty acid oxidation; and 2) the relationship between VDD and IR could develop through inflammation, since VDD is associated with increased inflammatory markers. ${ }^{37}$

Yet, Ministrini et $\mathrm{al}^{38}$ showed in subjects with obesity class III that 25(OH)D levels were higher in MHO than in insulin resistant individuals with obesity. In contrast, a study developed by Boonchaya-anant et $\mathrm{al}^{17}$ presented high prevalence of inadequacy but was not different between the two groups and $25(\mathrm{OH}) \mathrm{D}$ levels were not related to metabolic health status but correlated with degree of adiposity. Other research developed in France ${ }^{39}$ reinforced the absence of link between vitamin D status and IR in moderate obesity. This divergence could be explained by the difference between population studied, Al Masri et al's ${ }^{39}$ study worked with subjects with class I obesity and our study the prevalence was class III obesity.

Correlation between BMI and serum concentrations of VD was confirmed in the present study. With the phenotype MUHO, there is increased prevalence of some metabolic disorders.

Epidemiological studies have suggested that VDD is associated with the development of the MS, ${ }^{40,41}$ and others studies have shown increased prevalence of metabolic disorders and BMI. ${ }^{11,42}$ Additionally, the visceral body fat had the highest correlative association with increasing the features. Research has shown that more important than the total amount of body fat is your distribution, being that this fat in the abdominal area is a predictive factor for worsening VDD. ${ }^{43,44}$ This process may be attached to storage of VD in the adipocytes, reducing its bioavailability and causing a cascade of reactions by the hypothalamus which results in increased feelings of hunger and decreased energy expenditure. ${ }^{45}$ Lower $25(\mathrm{OH}) \mathrm{D}$ is associated with greater regional adiposity and this is stronger in visceral adipose tissue (VAT) than subcutaneous adipose tissue (SAT) and significant across the spectrum of body size. ${ }^{46}$ Otherwise, a study published by Cordeiro et $\mathrm{al}^{12}$ in 2017 informed that VD status, although quite often inversely related with obesity, does not seem to be particularly associated with measures of visceral and/or subcutaneous fat depots. The same occurs for the putative negative relationships of VD status with markers of glucoseinsulin homeostasis impairment; however, more studies are needed to clarify the relevance of VAT and SAT in VD status and metabolic dysfunction in obese environment.

Our study also presented high levels of LDL-c in MUHO subjects and research showed that, with increased adiposity, there is enhanced risk for developing IR leading to T2DM and cardiovascular disease, with an increased TG and LDL-c and a decreased HDL-c in the blood. ${ }^{47}$ As adiposity increases, the adipocytes produce and secrete proinflammatory cytokines and chemokines which enhance the inflamed state of the tissues. Dyslipidemia from increased adiposity also contributes to an elevation of LDL-c in the blood, leading to the formation of foam cells, plaque, and hypertension. ${ }^{48}$ Despite the relationship between VDD and impaired glucose tolerance not being completely understood, some randomized clinical trials show small effects of vitamin D3 on insulin secretion, IR, and HbAlc, and the effects are mainly visible in subjects with VDD and impaired glucose tolerance at baseline. $^{49}$ But it is known that VDD causes secondary hyperparathyroidism, and the high PTH concentration may cause glucose intolerance. ${ }^{50}$ Finally, all these biological processes may be associated with a low serum concentration of vitamin $\mathrm{D}$.

One limitation should be considered in the present study, because of its cross-sectional design, it was impossible to determine a causal relationship between VDD and metabolic disorders present in phenotypes of obesity. The strength of the study is from having a good sample size when compared with other studies, which allowed us to demonstrate relevant findings, as well as the unpublished result that an increase in serum concentrations of vitamin $\mathrm{D}$ increased the probability of existence of $\mathrm{MHO}$ phenotype.

\section{Conclusion}

The results showed the highest prevalence of inadequacy of serum concentrations of $25(\mathrm{OH}) \mathrm{D}$ and greater severity of this deficiency in individuals with MUHO phenotype. Low serum concentrations of this vitamin were associated with metabolic disorders, mainly IR, and demonstrated that a serum increase of $1 \mathrm{ng} / \mathrm{mL}$ of vitamin $\mathrm{D}$ increased by 1.051 the probability of occurrence of the metabolically healthy phenotype.

Monitoring the nutritional status of VD in individuals with obesity that present this type of phenotype may 
contribute to minimize the occurrence and development of diseases associated with obesity.

A key issue that still needs to be elucidated is how the inflammation and IR associated with obesity may be, partially, mediated by the reduction of circulating VD. Further investigations are needed in order to provide more information about new mechanisms in the physiopathology of MUHO phenotype when it is associated with VDD.

\section{Acknowledgments}

The authors acknowledge the contribution of Multidisciplinary Center of Bariatric and Metabolic Surgery Carlos Saboya that kindly provided the patients to be investigated. The authors also acknowledge Maria João Martins and Milton Severo (Department of Biomedicine, Unit of Biochemistry, Faculty of Medicine, University of Porto, Portugal) the overall organization and discussion of the paper. Finally, the cooperation of the subjects who took part in the study was greatly appreciated.

\section{Disclosure}

The authors declared no conflict of interests.

\section{References}

1. World Health Organization (WHO). Fact sheet obesity and overweight [Web page]. [Updated: 2016] 2013. Available from: http://www.who.int/ mediacentre/factsheets/fs311/en/. Accessed May 6, 2016.

2. Paniagua AJ. Nutrition, insulin resistance and dysfunctional adipose tissue determine the different components of metabolic syndrome. World J Diabetes. 2016;7(19):483-514. doi:10.4239/wjd.v7.i19.483

3. Wildman RP, Muntner P, Reynolds K, McGinn AP, Rajpathak S, Wylie-Rosett J. The obese without cardiometabolic risk factor clustering and the normal weight with cardiometabolic risk factor clustering: prevalence and correlates of 2 phenotypes among the US population (NHANES 1999-2004). Arch Intern Med. 2008;168: 1617-1624. doi:10.1001/archinte.168.15.1617

4. Kouvari M, Panagiotakos DB, Yannakoulia M, et al. ATTICA study investigators transition from metabolically benign to metabolically unhealthy obesity and 10-year cardiovascular disease incidence: the ATTICA cohort study. Metabolism. 2019;93:18-24. doi:10.1016/j. metabol.2019.01.003

5. Durward CM, Hartman TJ, Nickols-Richardson SM. All-cause mortality risk of metabolically healthy obese individuals in NHANES III. J Obes. 2012;2012:1-12. doi:10.1155/2012/460321

6. Reid IR, Bolland MJ, Grey A. Effects of vitamin D supplements on bone mineral density: a systematic review and meta-analysis. Lancet. 2014;383:146-155. doi:10.1016/S0140-6736(13)61647-5

7. Abbas MA. Physiological functions of vitamin D in adipose tissue. J Steroid Biochem Mol Biol. 2017;165:369-381. doi:10.1016/j. jsbmb.2016.08.004

8. Coin A, Giannini S, Minicuci N, et al. Limb fat-free mass and fat mass reference values by dual-energy X-ray absorptiometry (DEXA) in a 20-80 year-old italian population. Clin Nutr. 2012;31(4):506-511. doi:10.1016/j.clnu.2012.01.012
9. Yahyaoui S, Jmal L, Sammoud A, Abdenebi M, Jmal A, Boukthir S. Vitamin D deficiency is associated with metabolic syndrome in Tunisian children with obesity. Tunis Med. 2019;97(12):1353-1356.

10. Mogili KD, Karuppusami R, Thomas S, Chandy A, Kamath MS, Tk A. Prevalence of vitamin D deficiency in infertile women with polycystic ovarian syndrome and its association with metabolic syndrome - a prospective observational study. Eur J Obstet Gynecol Reprod Biol. 2018;229:15-19. doi:10.1016/j.ejogrb.2018.08.001

11. Cordeiro A, Pereira SE, Saboya CJ, Ramalho A. Association between $25(\mathrm{OH}) \mathrm{D}$ concentrations and metabolic syndrome components in class III obese subjects. Int J Med Med Sci. 2015;48(1):1597-1603.

12. Cordeiro A, Santos A, Bernardes M, Ramalho A, Martins M. Vitamin D metabolism in the human adipose tissue: could it explain the low vitamin D status in obesity? Horm Mol Biol Clin Investig. 2017;3(2).

13. Nematollahi HR, Hosseini R, Bijani A, et al. Interleukin 10, lipid profile, vitamin $\mathrm{D}$, selenium, metabolic syndrome, and serum antioxidant capacity in elderly people with and without cardiovascular disease: amirkola health and ageing project cohort-based study. ARYA Atheroscler. 2019;15(5):233-240.

14. Chen C, Chen Y, Weng P, et al. Association of 25- hydroxyvitamin $\mathrm{D}$ with cardiometabolic risk factors and metabolic syndrome: a mendelian randomization study. Nutr J. 2019;18(1):61. doi:10. 1186/s12937-019-0494-7

15. Kayaniyil S, Vieth R, Harris SB, et al. Association of 25(OH)D and PTH with metabolic syndrome and its traditional and non traditional components. J Clin Endocrinol Metab. 2011;96:168-175. doi:10.12 $10 /$ jc.2010-1439

16. Kim MK, Il Kang M, Won Oh K, et al. The association of serum vitamin D level with presence of metabolic syndrome and hypertension in middle-aged Korean subjects. Clin.Endocrinol. 2010;73: 330-338. doi:10.1111/j.1365-2265.2010.03798.x

17. Boonchaya-anant P, Holick MF, Apovian CM. Serum 25- hydroxyvitamin $\mathrm{D}$ levels and metabolic health status in extremely obese individuals. Obesity. 2014;22:2539-2543.

18. World Health Organization (WHO). World health statistics. 2011. Availble from: http://www.who.int/healthinfo/statistics/en/index. html. Accessed February 22, 2019.

19. Friedewald WT, Levy RI, Fredrickson DS. Estimation of the concentration of low-density lipoprotein cholesterol in plasma, without use of the preparative ultracentrifuge. ClinChem. 1972;18:499-502.

20. Matthews DR, Hosker JP, Rudenski AS, Naylor BA, Treacher DF, Turner RC. Homeostasis model assessment: insulin resistance and beta-cell function from fasting plasma glucose and insulin concentrations in man. Diabetologia. 1985;28:412-419. doi:10.1007/BF00280883

21. Holick MF, Binkley NC, Bischoff-Ferrari HA, et al. Evaluation, treatment, and prevention of vitamin D deficiency: an endocrine society clinical practice guideline. J Clin Endocrinol Metabol. 2011;96(7):1911-1930. doi:10.1210/jc.2011-0385

22. Hanwell HE, Vieth R, Cole DE, et al. Sun exposure questionnaire predicts circulating 25-hydroxyvitamin D concentrations in Caucasian hospital workers in southern Italy. J Steroid BiochemMol Biol. 2010;121:334-337. doi:10.1016/j.jsbmb.2010.03.023

23. Muñoz-Garach A, Cornejo-Pareja I, Tinahones FJ. Does metabolically healthy obesity exist? Nutrients. 2016;8(6):pii: E320. doi:10.3390/ nu8060320

24. Diaz-Ruiz A, Guzman-Ruiz R, Moreno NR, et al. Proteasome dysfunction associated to oxidative stress and proteotoxicity in adipocytes compromises insulin sensitivity in human obesity. Antioxid Redox Signal. 2015;23(7):597-612. doi:10.1089/ars.2014.5939

25. Martínez-Larrad MT, Anchuelo AC, Del Prado N, et al. Profile of individuals who are metabolically healthy obese using different definition criteria. A population-based analysis in the Spanish population. PLoS One. 2014;9(9):e106641. doi:10.1371/journal.pone.0106641

26. Stefan N, Haring HU, Hu FB, Schulze MB. Metabolically healthy obesity: epidemiology, mechanisms, and clinical implications. Lancet Diabetes Endocrinol. 2013;1(2):152-162. doi:10.1016/S2213-8587(13)70062-7 
27. Manzoni G, Oltolini A, Perra S, et al. Resting whole body energy metabolism in class 3 obesity; from preserved insulin sensitivity to overt type 2 diabetes. Diabetes Metab Syndr Obes. 2020;24 (13):489-497. doi:10.2147/DMSO.S228229

28. Bluher M. Are there still healthy obese patients? Curr Opin Endocrinol Diabetes Obes. 2012;19(5):341-346. doi:10.1097/ MED.0b013e328357f0a3

29. Yaribeygi H, Maleki M, Sathyapalan T, et al. The molecular mechanisms by which vitamin $\mathrm{D}$ improve glucose homeostasis: a mechanistic review. Life Sci. 2020;244:117305. doi:10.1016/j. lfs.2020.117305

30. Mackawy AM, Badawi ME. Association of vitamin D and vitamin D receptor gene polymorphisms with chronic inflammation, insulin resistance and metabolic syndrome components in type 2 diabetic Egyptian patients. Meta Gene. 2014;2:540-556. doi:10.1016/j. mgene.2014.07.002

31. Bikle DD. Vitamin D: newer concepts of its metabolism and function at the basic and clinical level. J Endocr Soc. 2020;4(2). doi:10.1210/ jendso/bvz038

32. Moradi N, Fadaei R, Rashidbeygi E, et al. Evaluation of changing the pattern of CTRP5 and inflammatory markers levels in patients with coronary artery disease and type 2 diabetes mellitus. Arch Physiol Biochem. 2020;23:1-6. doi:10.1080/13813455.2020.1742164

33. Rafique A, Etzerodt A, Graversen JH, Moestrup SK, Dagnæs-Hansen F, Møller HJ. Targeted lipid nanoparticle delivery of calcitriol to human monocyte-derived macrophages in vitro and in vivo: investigation of the anti- inflammatory effects of calcitriol. Int J Nanomedicine. 2019;14:2829-2846. doi:10.2147/IJN.S192113

34. Meghil MM, Hutchens L, Raed A, et al. The influence of vitamin D supplementation on local and systemic inflammatory markers in periodontitis patients: a pilot study. Oral Dis. 2019;25(5):1403-1413. doi:10.1111/odi.13097

35. Khan H, Kunutsor S, Franco OH, Chowdhury R. Vitamin D, type 2 diabetesand other metabolic outcomes: a systematic review and meta-analysis ofprospective studies. Proc NutrSoc. 2013;72:89-97.

36. Harinarayan CV, Arvind S, Joshi S, Thennarasu K, Vedavyas V, Baindur A. Improvement in pancreatic $\beta$-cell function with vitamin $\mathrm{D}$ and calcium supplementation in vitamin d- deficient nondiabetic subjects. EndocrPract. 2014;20(2):129-138.

37. Garbossa SG, Folli F. Vitamin D, sub-inflammation and insulin resistance. A window on a potential role for the interaction between bone and glucose metabolism. Rev Endocr Metab Disord. 2017;18 (2):243-258. doi:10.1007/s11154-017-9423-2

38. Ministrini S, Ricci MA, Daviddi G, et al. Determinants of high parathyroid hormone levels in patients with severe obesity and their relationship with the cardiometabolic risk factors, before and after a laparoscopic sleeve gastrectomy intervention. Obes Surg. 2020;30 (6):2225-2232. doi:10.1007/s11695-020-04453-Z
39. Al Masri M, Romain AJ, Boegner C, et al. Vitamin D status is not related to insulin resistance in different phenotypes of moderate obesity. ApplPhysiolNutrMetab. 2017;42(4):438-442.

40. Yoon H, Jeong DK, Park CE, et al. The association between gender difference with metabolic syndrome,metabolic syndrome score and serum vitamin D levels in Korean adults. Int J Food Sci Nutr. 2017;68:121-129. doi:10.1080/09637486.2016.1221899

41. Sung KC, Chang Y, Ryu S, Chung HK. High levels of serum vitamin $\mathrm{D}$ are associated with a decreased risk of metabolic diseases in both men and women, but an increased risk for coronary artery calcification in Korean men. CardiovascDiabetol. 2016;15(1):112. doi:10.11 86/s12933-016-0432-3

42. Tosunbayraktar G, Bas M, Kut A, Buyukkaragoz AH. Low serum 25 $(\mathrm{OH}) \mathrm{D}$ levels are associated to higher BMI and metabolicsyndrome parameters in adult subjects in Turkey. Afr Health Sci. 2015;15 (4):1161-1169. doi:10.4314/ahs.v15i4.15

43. Compher CW, Badellino KO, Boullata JI. Vitamin D and the bariatric surgical patient: a review. ObesSurg. 2008;18:220-224.

44. Misra A, Bhatt SP, Nigam P, et al. Independent associations of low 25 hydroxy vitamin D and high parathyroid hormonal levels with nonalcoholic fatty disease in Asian Indians residing in north India. $J$ Atherosclerosis. 2013;230:157-163. doi:10.1016/j.atherosclerosis. 2013.07.006

45. Park CY, Kim TY, Yoo JS, Seo Y, Pae M, Han SN. Effects of 1,25-dihydroxyvitamin D3 on the inflammatory responses of stromal vascular cells and adipocytes from lean and obese mice. Nutrients. 2020;12(2):364. doi:10.3390/nu12020364

46. Cheng S, Massaro JM, Fox CS, et al. Adiposity, cardiometabolic risk, and vitamin D status: the Framingham heart study. Diabetes. 2010;59:242-248. doi:10.2337/db09-1011

47. Zsido RG, Heinrich M, Slavich GM, et al. Association of estradiol and visceral fat with structural brain networks and memory performance in adults. JAMA Netw Open. 2019;2(6):e196126. doi:10.1001/ jamanetworkopen.2019.6126

48. Awad AB, Alappat L, Valerio M. Vitamin D and metabolic syndromerisk factors: evidence and mechanisms. Crit Rev Food Sci Nutr. 2012;52:103-112. doi:10.1080/10408391003785458

49. Lips P, Eekhoff M, van Schoor N, et al. Vitamin D and type 2 diabetes. J Steroid Biochem Mol Biol. 2017;173:280-285. doi:10.1016/j.jsbmb.2016.11.021

50. Ganji V, Tangpricha V, Zhang X. Serum vitamin D concentration $\geq 75$ $\mathrm{nmol} / \mathrm{L}$ is related to decreased cardiometabolic and inflammatory biomarkers, metabolic syndrome, and diabetes; and increased cardiorespiratory fitness in US adults. Nutrients. 2020;12(3):E730. doi: $10.3390 /$ nu12030730

Diabetes, Metabolic Syndrome and Obesity: Targets and Therapy

Dovepress

Publish your work in this journal

Diabetes, Metabolic Syndrome and Obesity: Targets and Therapy is an international, peer-reviewed open-access journal committed to the rapid publication of the latest laboratory and clinical findings in the fields of diabetes, metabolic syndrome and obesity research. Original research, review, case reports, hypothesis formation, expert opinion and commentaries are all considered for publication. The manuscript management system is completely online and includes a very quick and fair peer-review system, which is all easy to use. Visit http://www.dovepress.com/testimonials.php to read real quotes from published authors. 